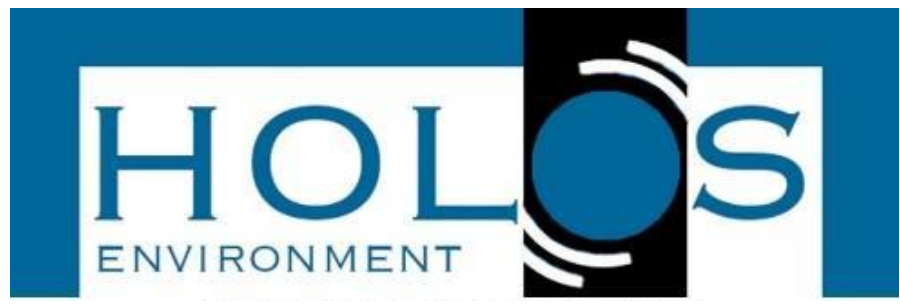

\title{
AVALIAÇÃO DA QUALIDADE DA ÁGUA DA LAGOA DE MARAPENDI - RIO DE JANEIRO, RJ
}

\section{ASSESSMENT OF THE MARAPENDI LAGOON WATER QUALITY IN RIO DE JANEIRO/RJ}

\author{
Gabriela Cardoso Lyra ${ }^{1}$; Lauren Nozomi Marques Yabuki ${ }^{1}$; \\ João Gabriel Thomaz Queluz'; Marcelo Loureiro Garcia ${ }^{1}$
}

Artigo recebido em: 27/11/2019 e aceito para publicação em: 12/12/2019.

DOI: http://dx.doi.org/10.14295/holos.v20i1.12366

Resumo: Lagoas costeiras são ambientes naturais, localizados entre o continente e o oceano, proporcionam uma série de serviços ambientais e servem como corpo receptor de águas pluviais. No entanto, estas zonas têm sido submetidas a constantes processos de degradação, devido às atividades antrópicas. O presente trabalho teve como principal objetivo realizar o diagnóstico ambiental da Lagoa de Marapendi, localizada no município de Rio de Janeiro, utilizando-se como base os dados históricos de qualidade da água de três estações de monitoramento, no período de 2010 a 2017. As variáveis utilizadas foram a Demanda Bioquímica de Oxigênio (DBO), Oxigênio Dissolvido (OD), Fósforo Total (PT), Série Nitrogenada e Coliformes Termotolerantes. Os dados foram comparados com os padrões estabelecidos pela legislação e os resultados, para todos os parâmetros físico-químicos, não estavam em conformidade com os valores da Resolução CONAMA n 357/2005 na maior parte do período, revelando que a Lagoa de Marapendi não apresenta um grau de qualidade adequado, provavelmente em razão de lançamentos irregulares de esgoto sem tratamento. A parte leste da Lagoa, por ter maior influência do regime de marés, apresentou os menores valores dos parâmetros de qualidade da água. O ponto localizado a montante da Lagoa apresentou a pior condição de qualidade ambiental, que pode ser justificada pela mesma razão, i.e., a baixa capacidade de renovação de águas nesta região da Lagoa.

Palavras-chave: Qualidade da Água. Parâmetros de Qualidade. Lagoas Costeiras. Complexo Lagunar de Jacarepaguá.

\begin{abstract}
Coastal lagoons are natural environments localized between the continent and the ocean, being of great importance to human beings due to a series of services provided, besides serving as rainwater receiving bodies. However, these zones have been subjected to constant degradation processes due to human activity. This study had as its main goal performing the environmental diagnosis of Marapendi lagoon (Rio de Janeiro city), using as a basis the water quality historical data from three monitoring stations, from 2010 until 2017. The variables used were the Biochemical Oxygen Demand (BOD), Dissolved Oxygen (DO), Total Phosphorus (TP), Nitrogen Series and thermotolerant coliforms. The data was compared with the patterns stablished by the legislation and the obtained results for all physicochemical parameters do not comply with the patterns established by the legislation in most of the time studied showing that the lagoon finds itself in bad environmental conditions, mainly due to the accelerated eutrophication process caused by the constant untreated sewage discharge into the water body. The eastern part of the lagoon, due to its greater influence of the tidal regime, presented the lowest values considering the analyzed parameters. However, the point located upstream of the lagoon
\end{abstract}

\footnotetext{
${ }^{1}$ Universidade Estadual Paulista (UNESP), Instituto de Geociências e Ciências Exatas (IGCE). São Paulo, SP. Emails: (gabi.cardoso.lyra@gmail.com, lauren.yabuki@unesp.br, igtqueluz@gmail.com, marcelo.garcia@unesp.br)
} 
presented the worst quality, due to partial silting up of this region and that can be justified by the low renewal capacity of its waters.

Keywords: Water Quality. Quality Parameters. Coastal Lagoons. Lagoon Complex of Jacarepaguá.

\section{INTRODUÇÃO}

As lagoas costeiras estão localizadas entre os ambientes marinho, terrestre e dulcícola, ocupando áreas deprimidas e alagadiças, caracterizando-se por possuir pouca profundidade e alta produtividade (KJERFVE, 1994). Estes ambientes funcionam como importantes indicadores ambientais, pois são receptores naturais de água e sedimentos, sendo, portanto, áreas representativas das condições ambientais de planícies costeiras e da qualidade da água da sua bacia de contribuição. Elas são encontradas na linha de costa de todo o mundo, representando cerca de $13 \%$ da área costeira mundial (KNOPPERS, 1994). Estes corpos aquáticos urbanos, além de servirem como zonas naturais de captação de escoamento de águas pluviais, oferecem valores estéticos e recreativos à população. Além disso, fornecem alimento e proteção para diversas espécies animais e vegetais (STEWART et al., 2008). No entanto, devido à baixa cota altimétrica aliada à sua condição lêntica, além de estarem localizadas em regiões de grande ocupação humana, estes sistemas são classificados entre os mais ameaçados do mundo, pois estão sujeitos a poluição e ocupação desordenadas (SANTOS, 2014).

No Brasil, as lagoas costeiras são encontradas ao longo de toda a sua costa, principalmente nas regiões Sul e Sudeste, destacando-se o estado do Rio de Janeiro, onde estão localizadas grande parte delas (MARINHO; FONSECA; ESTEVES, 2016).

Entretanto, nas últimas décadas, estes sistemas vêm sofrendo grandes transformações decorrente do intenso processo de degradação causado pelas atividades humanas, que submete estes ecossistemas a um forte estresse, contribuindo para a deterioração da qualidade de suas águas (KJERFVE, 1994).

Dentro deste contexto destaca-se o bairro da Barra da Tijuca no município do Rio de Janeiro, que vem passando por uma rápida expansão, tendo seu grande impulso de ocupação na década de 70 , mas que perdura em menor escala até hoje (RIGUETTI, 2009). No período entre 1960 a 2013, a população da Barra da Tijuca cresceu quase 10 vezes mais que a do município do Rio de Janeiro, causando um aumento significativo da densidade populacional da região (DATA RIO, 2013).

No entanto, o poder público nem sempre consegue acompanhar o ritmo dessa expansão, carecendo de infraestruturas urbanas de água e esgoto. Com isso, a região pode ser afetada pelo lançamento inadequado de esgoto doméstico e resíduos industriais em seus corpos d'água, prejudicando a qualidade das águas, com riscos de propagação de doenças de veiculação hídrica, além da ocupação irregular de suas margens. De fato, o Complexo Lagunar de Jacarepaguá (CLJ), particularmente a Lagoa de Marapendi, vem sofrendo um processo de eutrofização devido ao enriquecimento de nutrientes, potencializado pelo lançamento de despejos domésticos em suas águas (CERQUEIRA, 2006; SILVA, 2004). A degradação da 
qualidade da água tem causado modificações significativas em suas condições físicoquímicas, nas comunidades biológicas no ambiente e na produtividade do sistema, prejudicando o exercício dos usos múltiplos da Lagoa (PIMENTA; MARQUES, 2003).

Desse modo, o presente trabalho teve como objetivo principal realizar o diagnóstico ambiental da Lagoa de Marapendi com base na análise da condição de qualidade da água no período de 2010 a 2017, através de indicadores físico-químicos, gerando conhecimento a respeito da condição atual desta Lagoa, que vêm sofrendo com a intensa ocupação urbana em suas margens. Além disso, os dados gerados com o presente estudo podem vir a contribuir como uma importante ferramenta de planejamento e gerenciamento ambiental de suas águas e do uso da terra no seu entorno.

\section{MATERIAL E MÉTODOS}

\section{1 Área de estudo}

A lagoa costeira de Marapendi pertence ao Complexo Lagunar de Jacarepaguá (Figura 1), que é formado por mais três lagoas: Camorim, Jacarepaguá e Tijuca. Ela está localizada entre uma estreita faixa de praia e as lagoas mais interiores na zona oeste do munícipio do Rio de Janeiro. Com formato alongado, ela possui cerca de 10 $\mathrm{Km}$ de comprimento e 0,35 Km de largura, com profundidade média de 1,8 $\mathrm{m}$ e espelho d'água de $3,5 \mathrm{Km}^{2}$, sendo dividida em sete compartimentos semelhantes a bolsões, o que reduz a sua capacidade de renovação (RIGUETTI, 2009).

Figura 1 - Mapa de localização do Complexo Lagunar de Jacarepaguá e estações de monitoramento da Lagoa de Marapendi

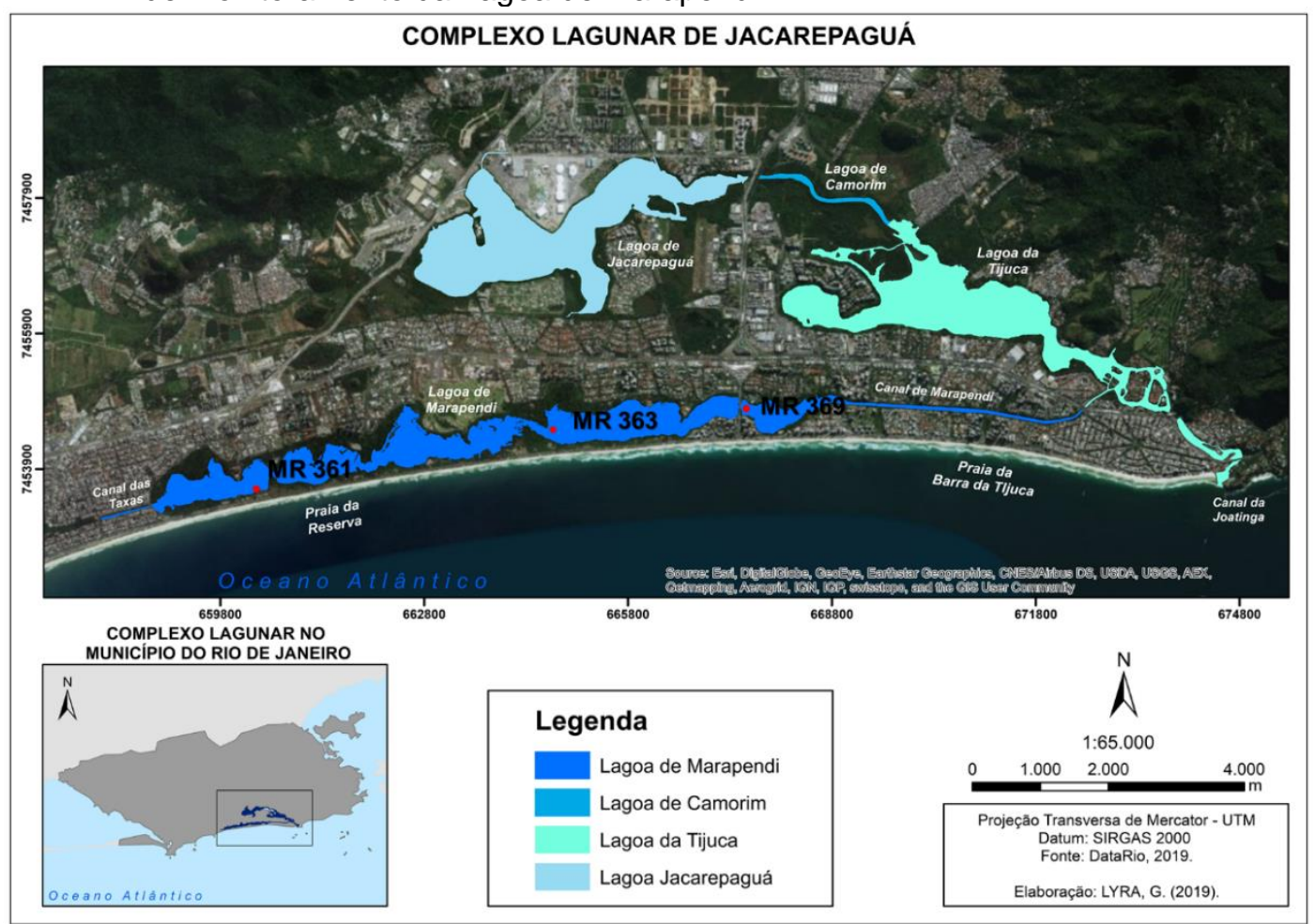

Fonte: Elaborado pelos autores (2019) 
Os maciços da Pedra Branca e da Tijuca constituem os divisores do sistema hidrográfico do Complexo Lagunar de Jacarepaguá (Figura 2a), cujos rios dessem as vertentes dessas montanhas e desaguam nas lagoas (Figura $2 b$ ), que por sua vez se ligam ao mar por meio do Canal da Joatinga (RIGUETTI, 2009). A bacia hidrográfica do Complexo abrange 16 bairros, sendo que a Lagoa de Marapendi está inserida no bairro da Barra da Tijuca (Figura 2c).

Figura 2 - a) Mapa de Localização dos Maciços da Pedra Branca e da Tijuca; b) Mapa da Bacia Hidrográfica de Jacarepaguá; c) Mapa dos bairros localizados na Bacia Hidrográfica de
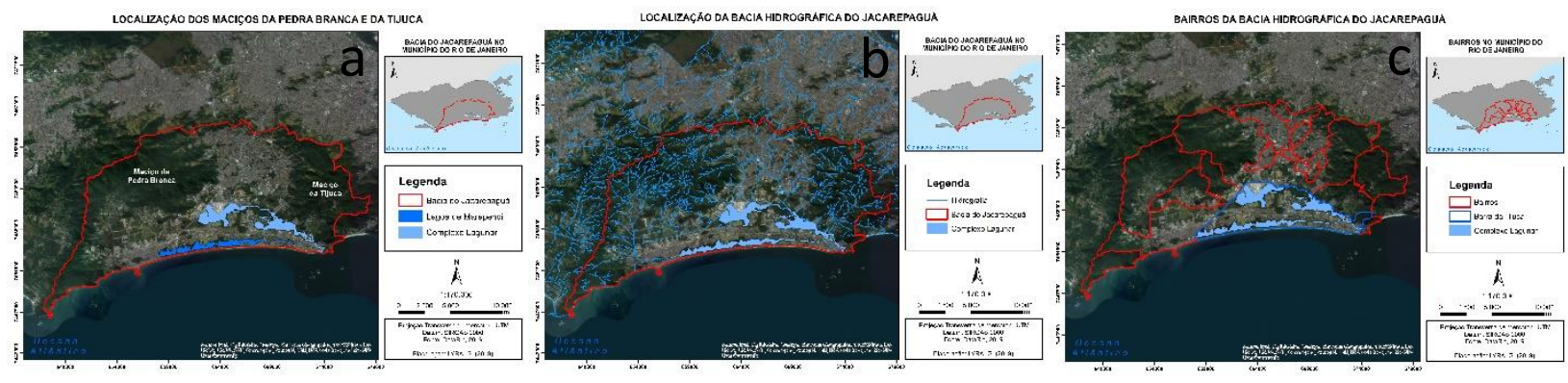

Jacarepaguá.

Fonte: Elaborado pelos autores (2019)

A Lagoa de Marapendi possui área de drenagem superficial de apenas $4,6 \mathrm{Km}^{2}$ e corresponde a única lagoa que não recebe afluência de praticamente nenhum rio, como pode ser visto na Figura 2b. Ela possui ligação com a Lagoinha a oeste por meio do Canal das Taxas, que se encontra assoreado e coberto por macrófitas em grande parte, dificultando a troca hídrica entre as duas lagoas por essa ligação. Já a leste, ela está ligada à Lagoa da Tijuca através do Canal de Marapendi. A partir daí, as águas são conduzidas para o mar pelo Canal da Joatinga. A Lagoa de Camorim é um pequeno trecho que conecta a Lagoa de Tijuca e a Lagoa de Jacarepaguá, que é a mais interiorizada do conjunto (RIGUETTI, 2009).

A Bacia Hidrográfica de Jacarepaguá possui cerca de $280 \mathrm{~km}^{2}$, sendo que o regime de chuvas é bastante influenciado pelas frentes frias vindas do Sul e pelo relevo, que aprisiona os ventos e as chuvas frontais. Assim, no verão há maior frequência e intensidade das chuvas que no inverno, característico do clima tropical presente no estado do Rio de Janeiro (MASTERPLAN, 2013).

O sistema de esgotamento sanitário do município do Rio de Janeiro é de responsabilidade da Companhia Estadual de Águas e Esgotos do Rio de Janeiro (CEDAE), sendo que, na Barra da Tijuca, foi concretizado somente em 2007 e no ano de 2009, iniciou-se a operação da Estação de Tratamento de Esgotos da Barra da Tijuca. Porém, o tempo em que o município esteve sem uma rede de esgoto adequada acarretou um grande passivo ambiental para as lagoas do CLJ. Neste contexto, estima-se que em 2000, aproximadamente 700 mil habitantes dos bairros da bacia hidrográfica da Barra da Tijuca, Jacarepaguá e Recreio dos Bandeirantes despejaram cerca de 40 mil kg/DBO.dia de esgotos, comprometendo os sistemas aquáticos da região (SEMADS, 2011). Devido a poluição hídrica, a Secretaria Estadual de Meio Ambiente (SMAC), no ano de 2007, proibiu a pesca e comercialização de peixes 
provenientes do Complexo Lagunar de Jacarepaguá e interditou as lagoas e o trecho inicial da praia da Barra para recreação, devido aos potenciais riscos para a saúde da população (GOMES et al., 2009).

\subsection{Levantamento de dados}

O Instituto Estadual do Ambiente (INEA) é o órgão público responsável pelo monitoramento da qualidade da água da Lagoa de Marapendi, que é realizado mensalmente por meio de três estações de monitoramento distribuídas em pontos estratégicos pela Lagoa. São analisados os principais parâmetros físico-químicos de qualidade de água, bem como o fitoplâncton e microcistinas.

No presente estudo foram utilizados os dados fornecidos pelo INEA de Oxigênio Dissolvido (OD), Nitrogênio Amoniacal $\left(\mathrm{NH}_{3}\right)$, Nitrito $\left(\mathrm{NO}_{2}^{-}\right)$, Nitrato $\left(\mathrm{NO}_{3}^{-}\right)$, Fósforo Total, Demanda Bioquímica de Oxigênio (DBO) e Coliformes Termotolerantes, medidos nas estações de monitoramento MR 361, MR 363 e MR 369 (Figura 1), no período de 2010 a 2017. No entanto, nem todos os anos e estações de amostragem foram considerados para alguns parâmetros, uma vez que não havia disponível todos os dados necessários. A Tabela 1 demonstra os períodos e estações considerados para cada parâmetro.

Tabela 1 - Períodos e estações considerados para avaliação de cada parâmetro

\begin{tabular}{lcc}
\hline \multicolumn{1}{c}{ Parâmetros } & Período & Estações \\
\hline $\begin{array}{l}\text { Oxigênio Dissolvido } \\
\text { Coliformes Termotolerantes }\end{array}$ & & \\
Nitrito & 2010 a 2017 & MR 361, MR 363 \\
Nitrato & & e MR 369 \\
DBO & & \\
Fósforo Total & & \\
Nitrogênio Amoniacal & 2010 a 2013 & MR 361 e MR 369 \\
\hline Fonte: Elaborado pelos autores (2019) &
\end{tabular}

Os dados obtidos foram compilados e organizados em planilhas. Posteriormente, foi realizada uma análise exploratória dos dados, na qual foram elaborados diferentes tipos de gráficos para cada parâmetro, a fim de selecionar aqueles que permitissem a melhor visualização do comportamento das variáveis ao longo do tempo. A maioria dos gráficos selecionados foram do tipo Boxplot, sendo que para alguns parâmetros com amplitude de dados muito alta, os dados foram representados por meio de gráficos de evolução da média aritmética. Além das análises por meio dos gráficos, foi realizada uma análise estatística por meio da ferramenta de Análise de Variância (ANOVA) a fim de verificar se havia diferença significativa entre as três estações de monitoramento.

Por fim, foi realizada a comparação dos valores com os padrões estabelecidos pela Resolução CONAMA no 357/2005 (BRASIL, 2005) para avaliar a qualidade da 
água das lagoas, que são enquadradas como Classe 2 (águas salobras). Neste contexto, estão dispostos na Tabela 2 os padrões estabelecidos pela Resolução para os parâmetros utilizados no presente trabalho e a linha vermelha inserida nos gráficos refere-se ao limite máximo estabelecido pala Resolução para águas salobras Classe 2.

Tabela 2 - Padrões estabelecidos pela Resolução CONAMA no 357/2005

\begin{tabular}{ll}
\hline \multicolumn{2}{c}{ Classe 2 - Águas Salobras } \\
\hline Parâmetros & Valor \\
Oxigênio Dissolvido (OD) & $>4,00 \mathrm{mg} / \mathrm{L}$ \\
Coliformes Termotolerantes & $<2500 \mathrm{por} 100 \mathrm{ml}$ \\
Fósforo total $\left(\mathrm{P}_{\text {total }}\right)$ & $<0,186 \mathrm{mg} / \mathrm{L}$ \\
Nitrato $\left(\mathrm{NO}_{3}^{-}\right)$ & $<0,70 \mathrm{mg} / \mathrm{L}$ \\
Nitrito $\left(\mathrm{NO}_{2}^{-}\right)$ & $<0,20 \mathrm{mg} / \mathrm{L}$ \\
Nitrogênio amoniacal $\left(\mathrm{NH}_{3}\right)$ & $<0,70 \mathrm{mg} / \mathrm{L}$ \\
\hline Fonte: Adaptado de Resolução CONAMA $\mathrm{n}^{\circ}=357 / 2005$
\end{tabular}

\section{RESULTADOS E DISCUSSÕES}

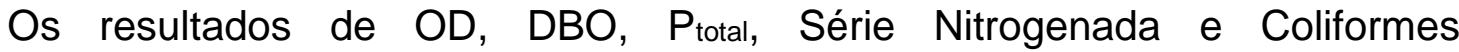
Termotolerantes são apresentados a seguir, no período de 2010 a 2017 da Lagoa de Marapendi. Quando houve diferença significativa estatística (valor-P inferior a 0,05) entre os conjuntos de dados por estações de monitoramento, os parâmetros de cada estação foram tratados separadamente (DBO, $P_{\text {total }}$ e Nitrogênio Amoniacal).

\subsection{0xigênio Dissolvido}

Os valores das medianas de oxigênio dissolvido das três estações em conjunto da Lagoa de Marapendi (Figura 3) oscilaram entre 4 e $6 \mathrm{mg} / \mathrm{L}$ no período de 2010 a 2014. Porém, nota-se uma tendência descendente das medianas entre 2014 e 2017, com uma redução de cerca de $3 \mathrm{mg} / \mathrm{L}$. Com exceção do ano de 2011, todos os outros anos registraram valores máximos elevados (acima de $10 \mathrm{mg} / \mathrm{L}$ ) quando comparados com as medianas, o que pode estar associado à elevada atividade fotossintética dos fitoplanctons. Além disso, é possível observar que os valores mínimos se apresentaram críticos em todos os anos, sendo que em 2012, 2016 e 2017 ocorreu inclusive a ausência desse componente, o que pode causar a morte de peixes e outras vidas aquáticas, servindo como um indicador de poluição da Lagoa. Por fim, ao se comparar as caixas do Boxplot com a legislação vigente, que estabelece uma concentração mínima de $4 \mathrm{mg} / \mathrm{L}$, é possível observar que na maior parte do tempo este padrão é atendido, exceto nos anos de 2013, 2016 e 2017. 
Figura 3 - Concentrações de Oxigênio Dissolvido (OD) nas estações MR 361, 363 e 369 (limite da Resolução CONAMA n $357 / 2005$ - linha horizontal vermelha)

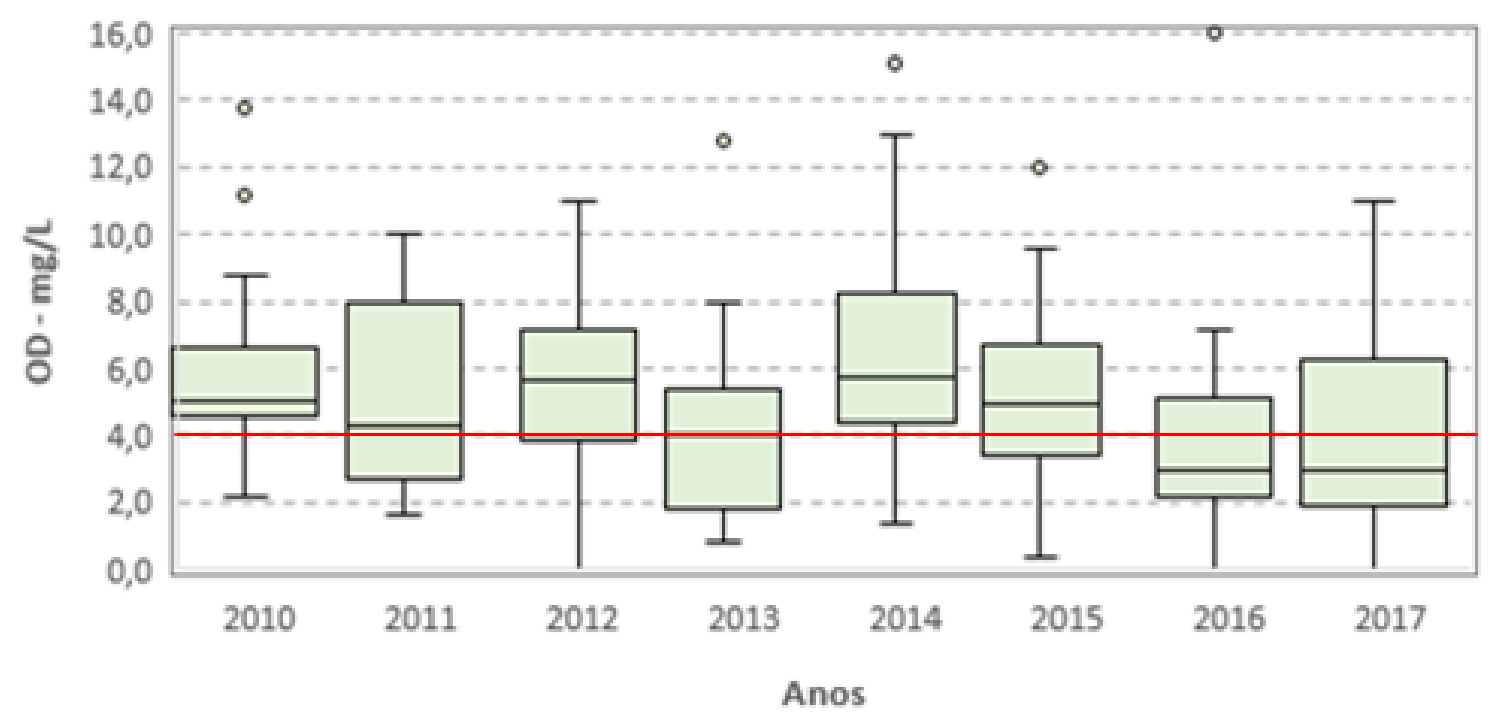

Fonte: Elaborado pelos autores (2019)

\subsection{Demanda Bioquímica de Oxigênio}

A maioria dos valores das medianas de DBO (Figura 4) da Estação MR 361 oscilaram entre 5 e $15 \mathrm{mg} / \mathrm{L}$, apresentando uma tendência de crescimento de $2010 \mathrm{a}$ 2013, quando se estabiliza a partir de 2014 até $2017 \mathrm{em}$ torno de $15 \mathrm{mg} / \mathrm{L}$. É importante destacar que no de 2017 foi registrado um valor de $110 \mathrm{mg} / \mathrm{L}$ (outlier), um valor extremamente elevado quando comparado ao restante dos dados, por isso a Figura 4 é apresentada sem os outliers a fim de obter uma melhor visualização dos dados.

A Estação MR 369 apresentou medianas ligeiramente menores que as da Estação MR 361. Entre 2010 a 2013 os valores apresentaram uma tendência ascendente, em que os outliers atingem o valor de $60 \mathrm{mg} / \mathrm{L}$. Já entre 2013 e 2016 ocorreu uma queda brusca das medianas de DBO, saindo de cerca de $15 \mathrm{mg} / \mathrm{L}$ para $6 \mathrm{mg} / \mathrm{L}$, aumentando novamente em 2017.

Os dados disponíveis da Estação MR 363 abrangeram apenas os anos de 2014 e 2015, sendo que em 2014 os valores do quartil estiveram entre 10 e $20 \mathrm{mg} / \mathrm{L}$ e em 2015 houve uma queda significativa, em que o quartil esteve entre 0 e $10 \mathrm{mg} / \mathrm{L}$. 
Figura 4 - Concentrações de Demanda Bioquímica de Oxigênio (DBO) nas estações MR 361, 363 e 369

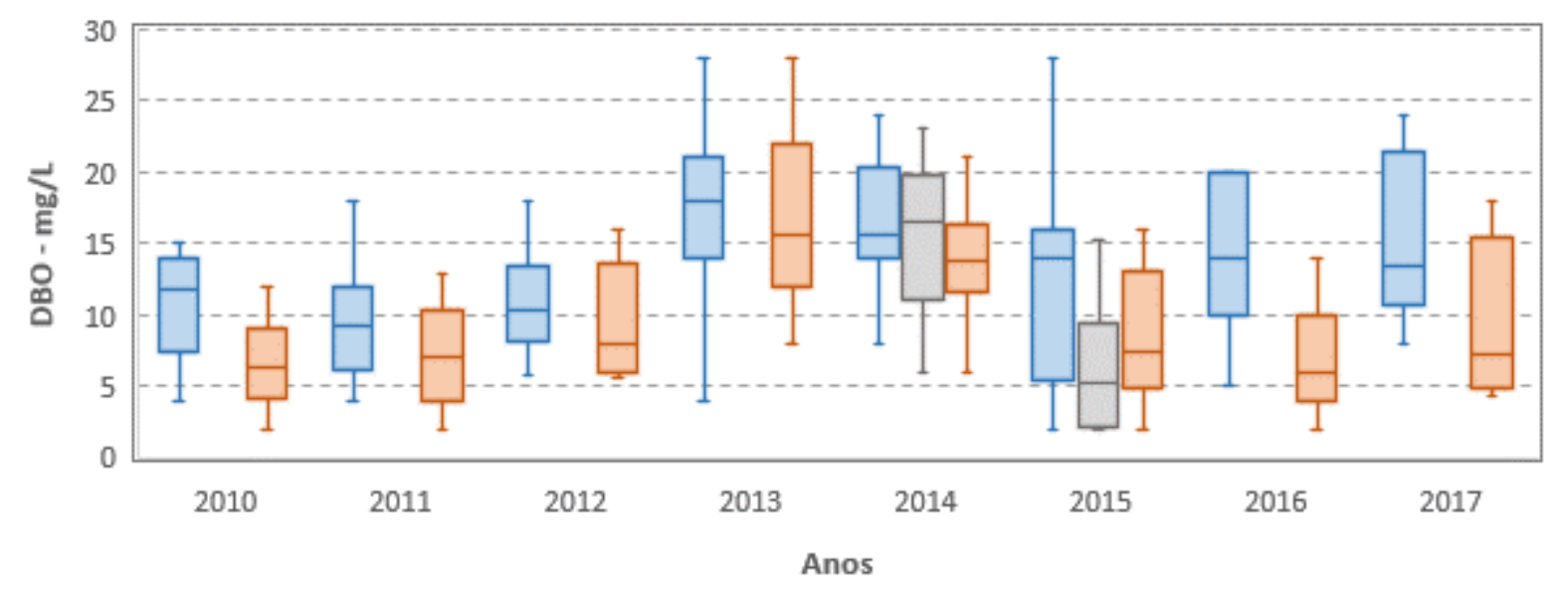

$\square$ MR $361 \square$ MR $363 \square$ MR 369

Fonte: Elaborado pelos autores (2019)

A legislação não estabelece um padrão para o parâmetro de DBO para águas salobras Classe 2, mas convém ressaltar que, de acordo com a Fundação Nacional de Saúde (FUNASA), é considerado uma baixa concentração de DBO, valores de 1 $\mathrm{mg} / \mathrm{L}$ a $10 \mathrm{mg} / \mathrm{L}$ para ambientes naturais límpidos (BRASIL, 2014). O lançamento de efluentes com elevada DBO, em corpos hídricos, causa um crescimento maior de bactérias anaeróbias a fim de estabilizar a matéria orgânica, reduzindo também a concentração de oxigênio dissolvido (Brasil, 2006). Neste contexto, ambas as estações atingiram valores mais elevados de DBO, típicos de áreas costeiras em processo de eutrofização e/ou de poluição por matéria orgânica.

\subsection{Fósforo Total}

$\mathrm{Na}$ Lagoa de Marapendi, as medianas de fósforo total (Figura 5) da Estação MR 361 oscilaram em torno de 1,0 e 1,5 mg/L, exceto nos anos de 2010 e 2012. Foram registrados valores máximos elevados em todos os anos, principalmente em $2010 \mathrm{e}$ 2014, que apontaram valores em torno de $2,5 \mathrm{mg} / \mathrm{L}$, enquanto no período de 2015 a 2017 os valores máximos se mantiveram constantes em torno de $1,5 \mathrm{mg} / \mathrm{L}$. Os valores mínimos também se mostraram elevados, acima de 0,5 mg/L, exceto em 2014.

Em relação a Estação MR 369, as medianas flutuaram entre 0,5 e 1,0 mg/L. É possível observar também que os valores mínimos tiveram uma ligeira redução entre 2010 e 2013. No entanto essa tendência não se mantém nos anos seguintes, quando eles aumentam em 2014 e se mantém até o ano de 2016 em torno de 0,5 mg/L para novamente apresentar uma pequena queda em 2017. Em relação aos outliers, no período de 2010 a 2014 foram registrados valores elevados de fósforo total, semelhantes aos dados observados da estação MR 361. 
Figura 5 - Concentrações de Fósforo Total (P) nas estações MR 361, 363 e 369 (limite da Resolução CONAMA $n^{\circ} 357 / 2005$ - linha horizontal vermelha)

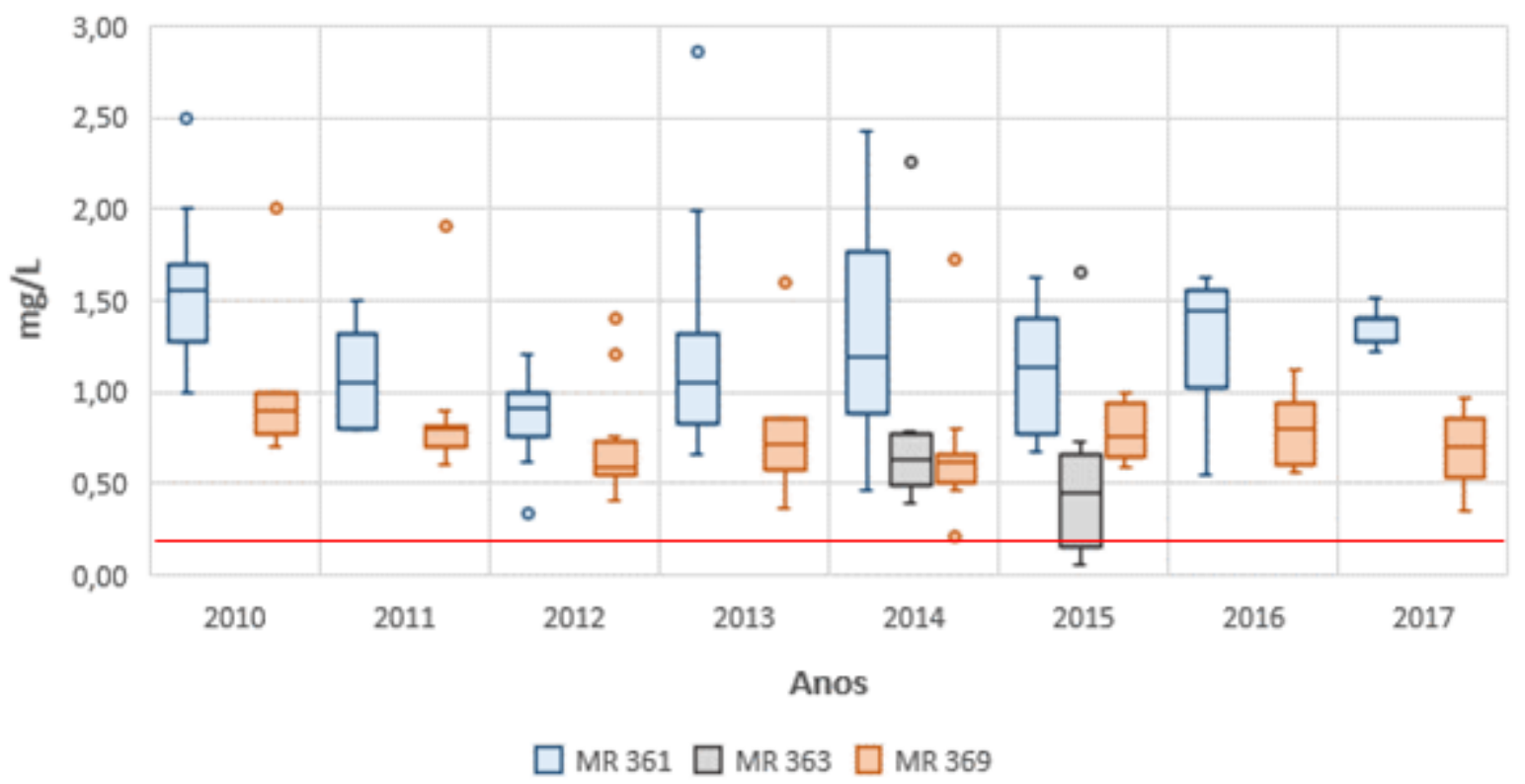

Fonte: Elaborado pelos autores (2019)

A partir da Figura 5 é possível perceber que os dados das três Estações de Monitoramento apresentaram concentrações relativamente diferentes de Fósforo Total, o que pode ser justificado pelo fato das estações estarem localizadas distantes uma da outra, sendo que a Estação MR 369 é a mais próxima do Canal de Marapendi, podendo apresentar uma maior influência pelo regime de marés.

Nota-se que em ambas as estações os valores apresentados ultrapassaram consideravelmente o limite máximo de $0,186 \mathrm{mg} / \mathrm{L}$ estipulado pela Resolução CONAMA n 357/2005, principalmente os dados apontados pela Estação MR 361, que registrou valores elevados em torno de $2,5 \mathrm{mg} / \mathrm{L}$.

Neste contexto, convém ressaltar que o fósforo é um importante nutriente para o desenvolvimento de algas e plantas aquáticas, caracterizando-se como o principal responsável pela eutrofização dos corpos d'água, além de limitar sua produtividade. Além disso, altas concentrações de fósforo podem estar associadas ao uso de fertilizantes na agricultura, que atingem o corpo d'água através do escoamento superficial, e ao despejo de esgoto inadequadamente tratado nos corpos d'água (CHAPMAN; KIMSTACH, 1996). No entanto, como na região não há presença de cultivos agrícolas, as altas taxas de fósforo total podem ser atribuídas a possíveis lançamentos de efluentes sem tratamento que possam estar ocorrendo na Lagoa.

\subsection{Série Nitrogenada}

A estação MR 361 apresentou quartil de até $12 \mathrm{mg} / \mathrm{L}$ de Nitrogênio Amoniacal (Figura 6a), enquanto a estação MR 369 apresentou quartil ligeiramente menor, de até $6 \mathrm{mg} / \mathrm{L}$. Esta diferença pode estar atribuída a distância entre elas, estando a MR 369 mais próxima ao Canal de Marapendi, o que facilita a troca hídrica nesta parte da 
Lagoa. A Estação MR 363 não foi considerada para análise devido à pouca quantidade de dados disponíveis.

Em ambas as estações é possível notar que os valores nos anos de 2010 e 2011 foram maiores que os valores registrados em 2012 e 2013. No entanto, mais de $90 \%$ dos dados, durante todo o período considerado, não atenderam ao limite estabelecido pela Resolução CONAMA oㅜ 357/2005, excedendo o limite máximo de $0,7 \mathrm{mg} / \mathrm{L}$ de Nitrogênio Amoniacal. Como a amônia serve como um indicador de contaminação recente por matéria orgânica, pois ocorre no estágio inicial da decomposição, é possível inferir que os pontos estão próximos de possíveis lançamentos de esgoto.

Em relação aos dados obtidos de Nitrito (Figura 6b), a maioria dos valores estiveram em conformidade com a Resolução CONAMA no 357/2005, abaixo do limite estipulado de $0,2 \mathrm{mg} / \mathrm{L}$, exceto nos anos de 2012 e 2013, em que concentrações mais altas foram registradas, o que pode prejudicar os organismos aquáticos. Além disso, é possível perceber um comportamento ascendente dos valores entre 2010 e 2013. Em 2014 ocorre uma queda brusca, mantendo-se constante entre 0,0 e 0,1 mg/L até 2017.

Comparando-se os dados de Nitrogênio Amoniacal e Nitrito, é possível perceber que no período de 2010 a 2013 ocorreu uma redução nas concentrações de Nitrogênio Amoniacal, enquanto houve um aumento nas concentrações de Nitrito durante o mesmo período. Esse fenômeno pode ser explicado devido ao processo de nitrosação realizado por bactérias aeróbias autotróficas, que realizam a oxidação do nitrogênio amoniacal em nitrito por meio de processos bioquímicos (CÂMARA, 2011).

As medianas de Nitrato (Figura $6 \mathrm{c}$ ) estiveram abaixo de $0,2 \mathrm{mg} / \mathrm{L}$ durante todo o período estudado, apresentando uma leve tendência descendente no período de 2011 a 2017. No geral, a maioria das concentrações de Nitrato atenderam ao limite de $0,7 \mathrm{mg} / \mathrm{L}$ estabelecido pela Resolução CONAMA 357/2005. No entanto, foram registrados outliers elevados de 2011 a 2015, acima de $1 \mathrm{mg} / \mathrm{L}$. 
Figura 6 - Resultados dos parâmetros: a) Nitrogênio Amoniacal nas estações MR 361 e 369; b) Nitrito nas estações MR 361, 363 e 369; c) Nitrato nas estações MR 361, 363 e 369. Limite da Resolução CONAMA n $357 / 2005$ - linha horizontal vermelha.

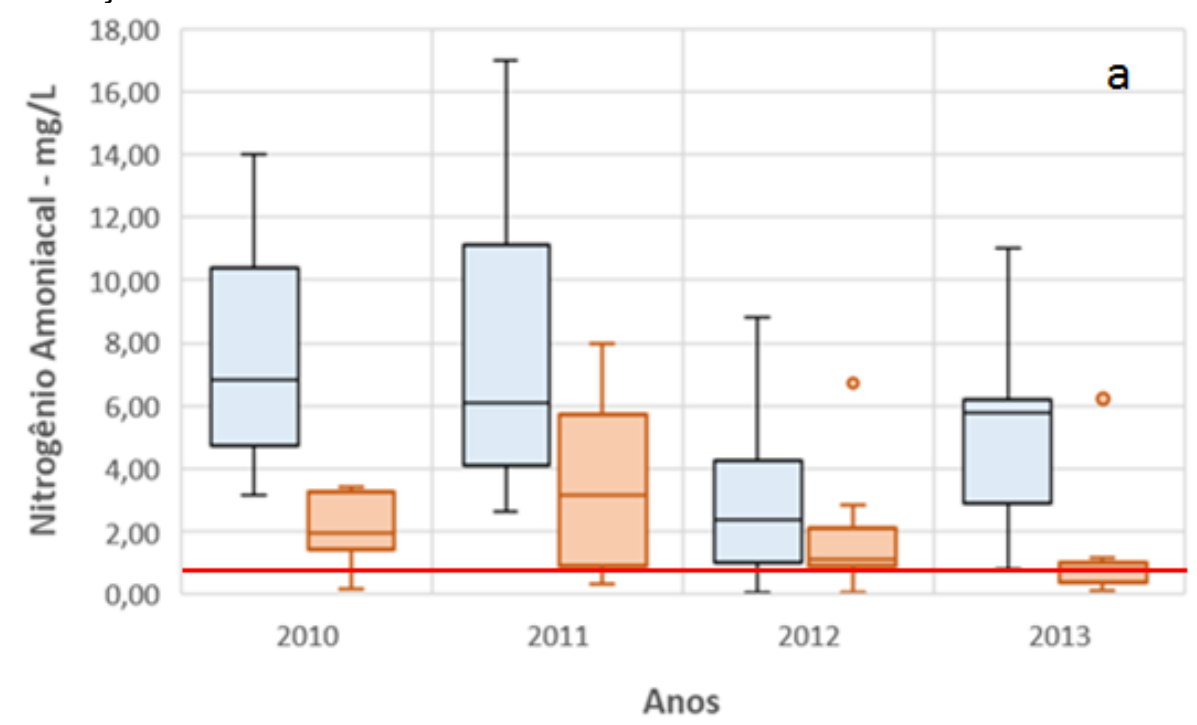

MR $361 \square$ MR 369
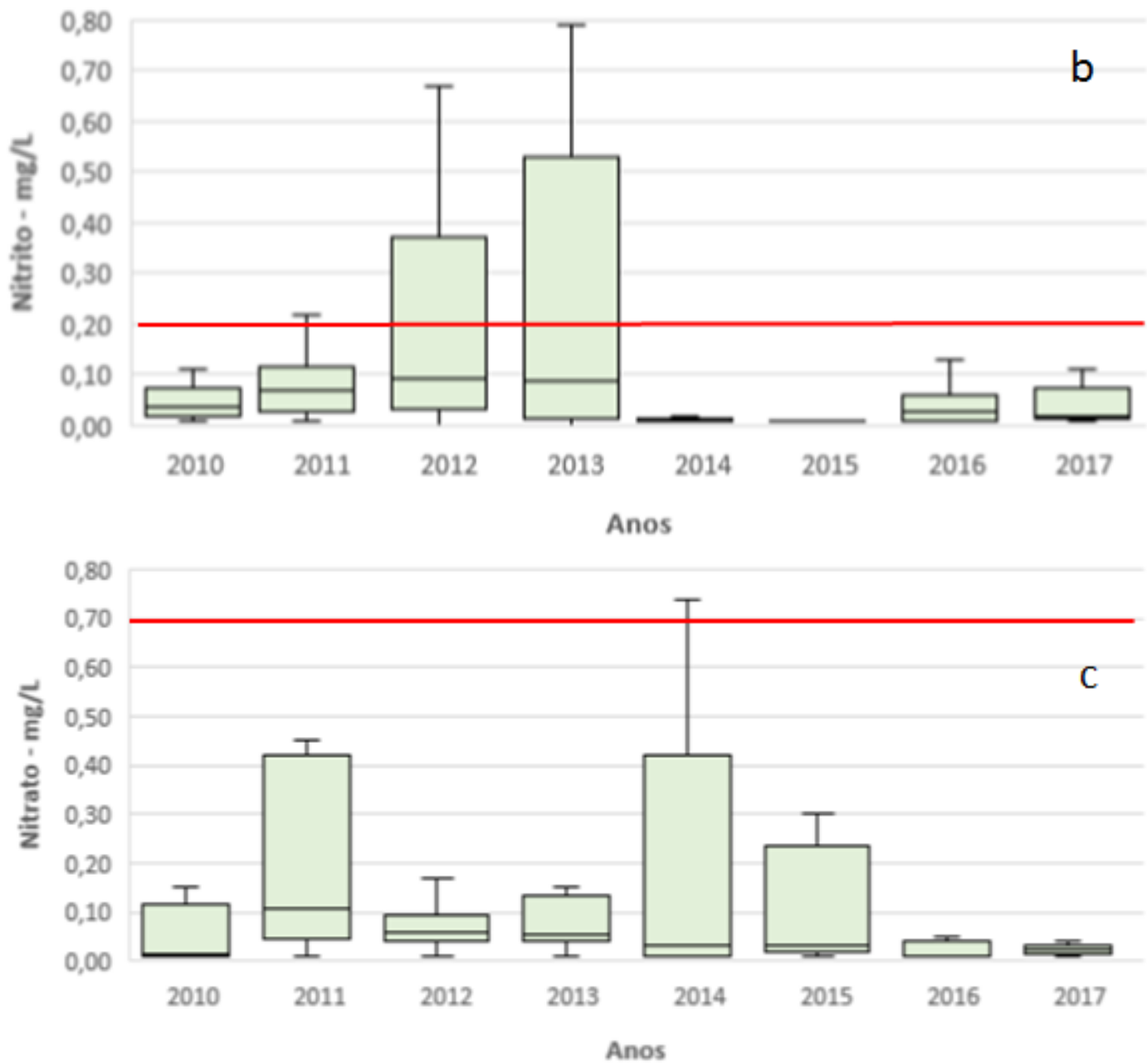

Fonte: Elaborado pelos autores (2019) 


\subsection{Coliformes Termotolerantes}

Os valores médios de coliformes termotolerantes apresentaram uma grande variação durante o período analisado, oscilando entre 5.000 a $25.000 \mathrm{NMP} / 100 \mathrm{~mL}$. Por meio da análise do gráfico de evolução temporal da média aritmética de cada ano (Figura 7), é possível observar que no ano de 2013 houve um aumento significativo da média, causado por valores máximos muito elevados registrados nesse ano, chegando a atingir $92.000 \mathrm{NMP} / 100 \mathrm{~mL}$ em uma das coletas. Em contrapartida, no ano de 2014, houve uma queda brusca da média, por motivos desconhecidos.

Além disso, é possível notar que em todos os anos os valores obtidos foram superiores ao padrão estabelecido pela Resolução CONAMA no 357/2005, que preconiza um limite de $2500 \mathrm{NMP} / 100 \mathrm{~mL}$ em $80 \%$ ou mais de pelo menos 6 amostras coletadas durante o período de um ano. Logo, estes valores indicam que existe contaminação fecal, porém não é possível afirmar que seja humana.

Figura 7 - Média aritmética do parâmetro Coliformes Termotolerantes nas estações MR 361, 363 e 369 (limite da Resolução CONAMA n 357/2005 - linha horizontal vermelha)

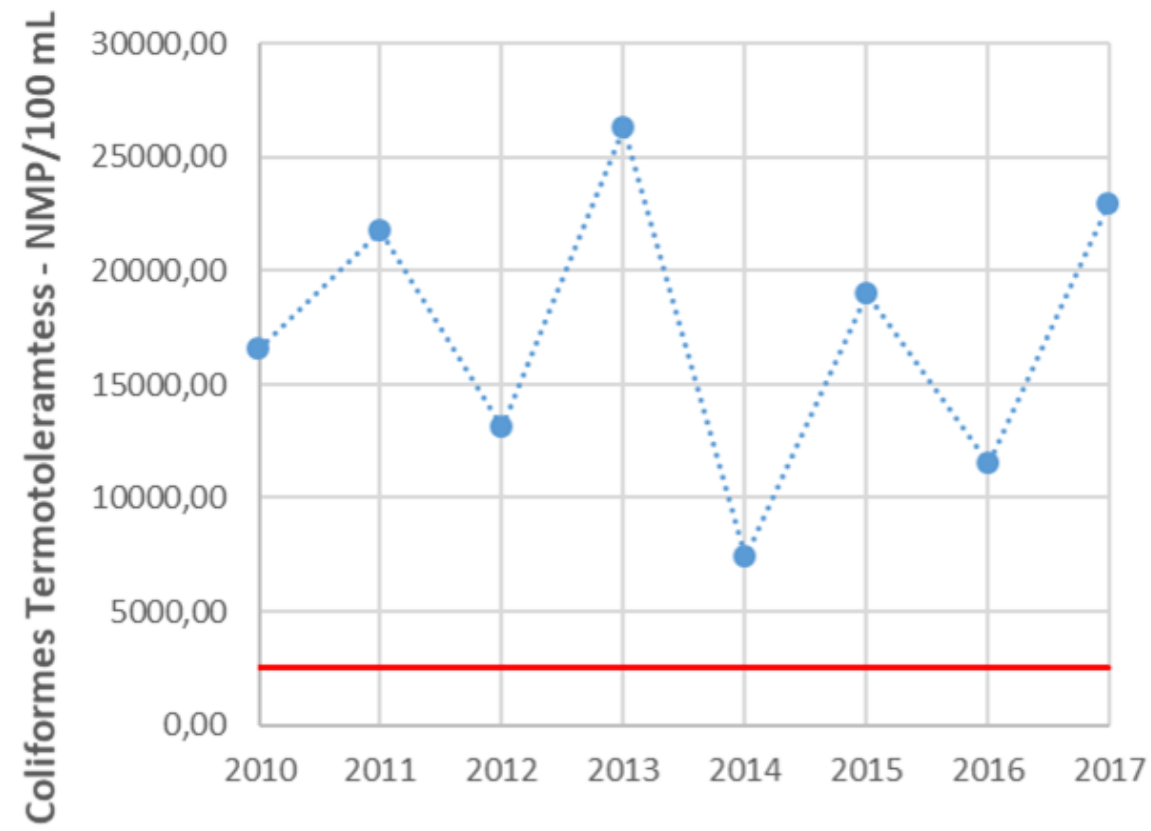

Anos

Fonte: Elaborado pelos autores (2019)

Correlacionando os valores médios de coliformes termotolerantes com os dados amostrados de Oxigênio Dissolvido, no ano de 2013 os dados se concentram no quartil com valores de OD entre 2 e $6 \mathrm{mg} / \mathrm{L}$ e de cerca de $25.000 \mathrm{NMP} / 100 \mathrm{~mL}$. Enquanto no ano de 2014 os dados se concentram entre 4 e $8 \mathrm{mg} / \mathrm{L}$ de OD e cerca de $11700 \mathrm{NMP} / 100 \mathrm{~mL}$ de coliformes. Esta correlação indica que a diminuição das concentrações de OD e o aumento das taxas de coliformes termotolerantes no corpo d'água pode estar associada as descargas de esgoto sanitário na lagoa. 


\section{CONCLUSÕES}

A partir desse trabalho foi possível concluir que, os valores dos parâmetros físico-químicos de qualidade da água, como Oxigênio Dissolvido, Demanda Bioquímica de Oxigênio, Fósforo Total, Nitrogênio Amoniacal, Nitrito e Nitrato, medidos no período de 2010 a 2017 na Lagoa de Marapendi, não estão em conformidade com os padrões estabelecidos pela legislação na maior parte do tempo, refletindo condições inapropriadas de qualidade ambiental da Lagoa de Marapendi, não sendo propícia nem mesmo à recreação e pescado. É possível que haja a contaminação antrópica por matéria orgânica, principalmente na região em que a estação MR361 está localizada, e que haja simultaneamente o fenômeno de eutrofização. Embora o sistema de esgotamento sanitário da Barra da Tijuca já esteja implantado pela CEDAE em boa parte da região, as altas concentrações de DBO, Nitrogênio Amoniacal, Fósforo Total e Coliformes Termotolerantes registradas durante todo o período estudado em conjunto com os valores críticos de Oxigênio Dissolvido indicam que a lagoa tem servido como corpo receptor de efluentes sem tratamento. Este fenômeno é sentido principalmente na parte oeste da Lagoa, onde está localizada a estação MR361, próximo ao Canal das Taxas que atualmente está parcialmente assoreado, dificultando a troca hídrica nesta parte da lagoa. Já a estação MR369 encontra-se próxima ao Canal de Marapendi na porção leste da lagoa, podendo apresentar maior influência pelo regime de marés, o que justifica suas menores concentrações. A fim de restabelecer o equilíbrio ambiental do ecossistema aquático da Lagoa de Marapendi, se faz necessário a adoção de medidas que visem à recuperação da qualidade das águas de todas as lagoas do Complexo Lagunar de Jacarepaguá, bem como os rios que desaguam nelas.

\section{REFERÊNCIAS}

BRASIL. Ministério do Meio Ambiente. Conselho Nacional do Meio Ambiente. Resolução CONAMA no 357, de 17 de março de 2005. Dispõe sobre a classificação dos corpos de água e diretrizes ambientais para o seu enquadramento, bem como estabelece as condições e padrões de lançamento de efluentes, e dá outras providências. Disponível em: http://www2.mma.gov.br/port/conama/legiabre.cfm?codlegi=459. Acesso em: 12 set. 2019.

BRASIL. Ministério da Saúde. Secretaria de Vigilância em Saúde. Vigilância e controle da qualidade da água para consumo humano. Brasília: Ministério da Saúde, 2006. 212 p.

BRASIL, Ministério da Saúde. Fundação Nacional de Saúde (FUNASA). Manual de controle da qualidade da água para técnicos que trabalham em ETAs. Brasília, 2014. Disponível em: http://www.funasa.gov.br/site/wpcontent/files $\mathrm{mf} / \mathrm{manualcont}$ quali agua tecnicos trab emetas.pdf: Acesso em: 19 set. 2019.

CÂMARA, F. M. M. Avaliação da Qualidade da Água do Rio Poti da Cidade de Teresina, Piauí. Dissertação (Doutorado), Pós-Graduação em Geografia, UNESP, Rio Claro, SP, 2011. 153 p. Disponível em: https://repositorio.unesp.br/handle/11449/104342. Acesso em: 24 set. 2019. 
CEDAE. Companhia Estadual de Águas e Esgotos. Programa de Saneamento da Barra da Tijuca, Recreio dos Bandeirantes e Jacarepaguá - PSBJ. Rio de Janeiro, 2014. Disponível em: https://www.cedae.com.br/saneamento barra recreio jacarepagua. Acesso em: 9 out. 2019.

CERQUEIRA, L. F. F. Os Impactos dos Assentamentos Informais de Baixa Renda nos Recursos Hídricos e na Saúde Coletiva: o caso da bacia hidrográfica da baixada de jacarepaguá. 2006. 165 f. Dissertação (Mestrado em Engenharia Ambiental) - Programa de Pós-graduação em Engenharia Ambiental, Universidade do Estado do Rio de Janeiro, Rio de Janeiro, RJ. Disponível em:

http://www.peamb.eng.ueri.br/trabalhosconclusao/2006/LuizFernandoFloresCerqueirpeamb2 006.pdf. Acesso em: 10 out. 2019.

CHAPMAN, D.; KIMSTACH, V. Selection of water quality variables. In: CHAPMAN, D. Water quality assessment: a guide to use of biota, sediments and water in environmental monitoring. 2. ed. Cambridge University Press, 1996. p. 74-133.

DATA RIO. Nota técnica 17: caracterização da região metropolitana do Rio de Janeiro (setembro/2013). Disponível em:http://www.data.rio/datasets/nota-t\%C3\%A9cnica-17caracteriza\%C3\%A7\%C3\%A3o-da-regi\%C3\%A3o-metropolitana-do-rio-de-janeiro-setembro2013. Acesso em: 10 out.2019.

GOMES, A. M. et al. Florações de cianobactérias tóxicas em uma lagoa costeira hipereutrófica do Rio de Janeiro/RJ (Brasil) e suas Consequências para Saúde Humana. Revista Oncologia Brasiliensis, Rio de Janeiro, RJ. v. 13, n. 1, pp. 329-345, 2009. Disponível em: https://revistas.ufri.br/index.php/oa/article/download/8075/6526. Acesso em: 15 out. 2019.

KJERFVE, B. Coastal lagoon processes. Amsterdam: Ed. Elsevier Oceanography, 1994, p. 1-8.

KNOPPERS, B. Aquatic primary production. In: KJERFVE, B. Coastal Lagoon processes. Amsterdam: Ed. Elsevier Oceanography, 1994, p. 221-241.

MASTERPLAN. Relatório ambiental simplificado das obras de recuperação ambiental do complexo Lagunar de Jacarepaguá. Consultoria de Projetos de Meio Ambiente. Capítulo 3 - Diagnóstico Ambiental da Área de Influência. 450 p. Rio de Janeiro, 2013. Disponível em: http://eadterrazul.org.br/pdf/Documentos/RAS\%20DRAGAGEM/3.\%20DIAGNOSTICO\%20A MBIENTAL.pdf. Acesso em: 28 set. 2019.

MARINHO, C. C.; FONSECA, A. L. S.; ESTEVES, F. A. Impactos antrópicos nas lagoas costeiras do norte do estado do Rio de Janeiro: uma revisão sobre a eutrofização artificial e gases de efeito estufa. RBPG, Brasília, v. 13, n.32, p. 703 - 728, 2016. Disponível em: https://www.researchgate.net/publication/315380287 Impactos antropicos nas lagoas cost eiras do norte do estado do Rio de Janeiro uma revisao sobre a eutrofizacao artifici al e gases de efeito estufa. Acesso em: 19 set. 2019.

PIMENTA, L. C.; MARQUES, J. S. Consequências de uma ocupação intensa para o ambiente lagunar de jacarepaguá: o caso das lagoas de Jacarepaguá, Camorim e Tijuca. Revista Geo-UERJ. v. 1, n. especial, p. 2326-2333, Rio de Janeiro, 2003.

RIGUETTI, A. L. Avaliação espaço-temporal do grau de trofia em lagoas costeiras da cidade do Rio de Janeiro: aplicação de índices de estado trófico. Dissertação (Mestrado em Química) Programa de Pós-graduação em Química, UERJ, Rio de Janeiro, 2009.

Disponível em: 
http://bdtd.ibict.br/vufind/Record/UERJ 869b235bbdfa16f25105aa7567cce230. Acesso em: 20 out. 2019.

SANTOS, M. R. Evolução temporal da eutrofização no Complexo Lagunar de Jacarepaguá. Dissertação (Dissertação em Engenharia Ambiental) - Universidade Federal do Rio de Janeiro, Rio de Janeiro, 2014. Disponível em:

http://monografias.poli.ufri.br/monografias/monopoli10014039.pdf. Acesso em: 6 out. 2019.

SEMADS. Ambiente das águas no Estado do Rio de Janeiro. Cooperação Técnica Brasil Alemanha/Projeto PLANÁGUA, Rio de Janeiro, RJ, 2001.

SILVA, G. Impactos ambientais resultantes do processo de ocupação da Barra da Tijuca. Dissertação (Mestrado), Universidade Federal do Rio de Janeiro, Rio de Janeiro, RJ, 2004.

STEWART, J. R. et al. The coastal environment and human health: microbial indicators, pathogens, sentinels and reservoirs. Environ Health, v. 7, supl. 2, p. 1476- 1069X, 2008. Disponível em: https://www.ncbi.nlm.nih.gov/pmc/articles/PMC2586716/. Acesso em: 5 out. 2019. 